\title{
Effects of Omega - 3 Fatty Acid Supplementation on Aquaponic System-raised Tilapia
}

\author{
Tiffany Hough ${ }^{1}$, Mohammad Qasim ${ }^{2}$, Christina Glaze ${ }^{3}$, Elliott Blumenthal ${ }^{1}$, Ahmed Mustafa ${ }^{1, *}$ \\ ${ }^{1}$ Department of Biology, Indiana University-Purdue University Fort Wayne, USA \\ ${ }^{2}$ Department of Chemistry, Indiana University-Purdue University Fort Wayne, USA \\ ${ }^{3}$ Get Fresh Farms, Fort Wayne Metals, USA
}

Copyright (C) 2015 by authors, all rights reserved. Authors agree that this article remains permanently open access under the terms of the Creative Commons Attribution License 4.0 International License

\begin{abstract}
Tilapia does not naturally contain high levels of omega-3 fatty acids which can be altered through feed supplementation. This study evaluates the effects of omega-3 fatty acid supplementation on tilapia growth and muscle tissue composition, especially the ability of tilapia to retain omega-3 fatty acids, raised in aquaponics system. Tilapia were fed linseed oil (LO) and sunflower oil (SO) supplemented feeds for 12 weeks and growth was measured at 0,6 , and 12 weeks. Omega- 3 muscle tissue retention was measured at 12 weeks. The condition factor significantly increased between 6 and 12 weeks for both LO and SO. At week 12 the condition factor of the negative control (NC) was significantly lower than both LO and SO. LO retained more of some omega-3 fatty acids than SO, however they were not significantly different using either method. $\mathrm{NC}$ had higher total omega-3 values than $\mathrm{LO}$ and $\mathrm{SO}$ according to both methods; however NC also had the highest saturated and total fat. This study determined that increasing fatty acids in the diet resulted in increased growth and a healthier body composition overall for tilapia; however it did not conclusively determine the effect of supplementation on omega-3 retention.
\end{abstract}

Keywords Omega-3, Tilapia, Aquaponics, Stress, Immune Response

\section{Introduction}

Increase in the worldwide human population has resulted in an increased need for food, especially nutrient dense protein sources. Fish is a vital source of food, accounting for approximately $16 \%$ of the animal protein consumed worldwide [1]. Aquaculture is rising in prevalence in response to food needs and problems with traditional capture fishing. It represents a major source of food especially in developing countries or countries where livestock farming is not feasible. The per capita consumption of food fish from aquaculture increased from $0.7 \mathrm{~kg}$ in 1970 to $7.8 \mathrm{~kg}$ in 2008 [2]. One problem with current aquaculture techniques is that commercial compound feeds for omnivorous species like tilapia contain on average $15 \%$ fish meal and $1 \%$ fish oil resulting in a ratio of 1.41 of wild fish used to farm fish produced [3].This increases the demand for fish meal and fish oil without a sustainable return in terms of production for human consumption [3]. In this study we utilized commercial feed supplemented with linseed oil as an omega-3 fatty acid source and looked at growth. If the use of this source of fatty acids produces no negative effects, a trial with custom feed utilizing linseed oil may be promising and allow for the use of alternatives to fish oil in feeds.

Studies have shown that many freshwater fish, including tilapias, do not contain significant amounts of omega-3 fatty acids especially nutritionally important Docosahexaenoic Acid (DHA) and Eicosapentaenoic Acid (EPA) [4]. Previous studies have demonstrated that supplementation of tilapia feed with omega-3 fatty acids can increase the amount of these fatty acids in the muscle tissue $[4,5,6]$. This is relevant to human nutrition as research trials have demonstrated that omega 3 fatty acid supplementation reduces cardiovascular reactivity, inflammation, and anxiety in people experiencing stress $[7,8]$.

This study investigates the effects of omega-3 supplementation on growth in tilapia. It also investigates the effect of supplementation on omega-3 fatty acid retention in muscle tissue and overall muscle composition; thereby potentially increasing the sustainability, quality, and marketability of aquaculture products.

\section{Materials and Methods}

Disease free juvenile tilapia (Oreochromis niloticus $X$ Oreochromis aureus) were obtained from a certified fish hatchery and kept under optimal conditions in a recirculating aquaponics system throughout the experiment. One hundred sixty fish were randomly assigned to four tanks representing 
two replicates of two treatment groups. Fish were then allowed to acclimate to experimental tanks for two weeks prior to beginning the experiment. Five fish were kept out of the system in a separate tank to serve as a negative control. The fish were mixed sex (evidenced during dissection) with screens on the tanks to prevent any young from reaching the plant beds and feeding on roots. The photoperiod was 24 hours light to allow maximum growth. An EXECH Exstik EC500 meter (Extech Instruments Corporation, Nashua, New Hampshire, U.S.A.) was used to measure pH, salinity, TDS, and temperature on a daily basis. A LaMotte Fresh Water Testing Kit (LaMotte Company, Chestertown, Maryland, U.S.A.) was used to measure ammonia, nitrite, alkalinity, hardness, and $\mathrm{CO}_{2}$. Ammonia and nitrite were measured daily and remaining parameters measured as needed. A YSI DO Meter (YSI Incorporated, Yellow Springs, Ohio, U.S.A.) was used to measure DO and a Hach NitraVER5 Nitrate Reagent (Hach Company, Loveland, Colorado, U.S.A.) used to measure nitrates. These were also done daily. All parameters were maintained at levels considered safe and optimal (Table 1).

Table 1. Recommended water quality parameters for tilapia and water quality conditions during experimental period. Conditional data is expressed as mean $\pm \mathrm{SD}$.

\begin{tabular}{|c|c|c|}
\hline $\begin{array}{c}\text { Water Quality } \\
\text { Parameters }\end{array}$ & $\begin{array}{c}\text { Recommended } \\
\text { Concentration for Tilapia } \\
\text { (Losordo, 1997; Pompa, } \\
1999)\end{array}$ & $\begin{array}{c}\text { Conditions During } \\
\text { Experimental Period }\end{array}$ \\
\hline $\begin{array}{c}\text { Dissolved } \\
\text { Oxygen (mg/L) }\end{array}$ & $6-9$ & $6.82 \pm 1.0$ \\
\hline $\begin{array}{c}\text { Ammonia } \\
\left(\mathrm{NH}_{3}\right)(\mathrm{mg} / \mathrm{L})\end{array}$ & $0.08-1$ & $0.68 \pm 0.5$ \\
\hline $\begin{array}{c}\mathrm{Nitrite}\left(\mathrm{NO}_{2}\right) \\
(\mathrm{mg} / \mathrm{L})\end{array}$ & $<5$ & $0.68 \pm 0.6$ \\
\hline $\mathrm{pH}$ & $6.0-7.5$ & $6.58 \pm 0.1$ \\
\hline
\end{tabular}

\subsection{Treatments}

The sunflower oil (SO) treatment group received Purina
Mills Aquamax Grower 400 3/32" (2.4mm) commercial feed supplemented with sunflower oil at 5\% total ingredients [4, 5, $9,10]$. Sunflower oil is not rich in omega 3 fatty acids and served to demonstrate any effects from the addition of lipids to the overall diet. The second treatment group received the same feed supplemented with omega 3 fatty acids in the form of flaxseed oil (FO) at $5 \%$ total ingredients $[4,5,9,10]$. The negative control (NC) received the commercial feed without any alterations. All groups were fed three times daily to satiation and the amount of food recorded by weight in grams. The experiment ran for 12 weeks $[4,6,11]$ with sampling at time 0,6 , and 12 weeks.

Commercial feed was purchased from Milan Center Feed \& Grain (New Haven, IN) and oils were purchased from Sigma-Aldrich. Oils were applied to dry feed at $5 \%$ total ingredients by weight and mixed thoroughly until homogeneity was reached [11] (Table 2). The feed was then allowed to dry for 24 hours before being stored in airtight containers.

\subsection{Sampling}

Sampling was performed at zero, six, and twelve weeks. A sample of five fish from each tank was taken and euthanized using Tricane Methane Sulphonate (MS222) at $200 \mathrm{mg} / \mathrm{l}$ within 2 minutes of catching to reduce handling stress. The fish were then transported to campus for data collection and analysis. Hematocrit, plasma protein, blood glucose, condition factor, spleen somatic index, and macrophage phagocytic activity were determined at each sampling. Muscle tissue was removed, flash frozen in liquid nitrogen, then vacuum sealed and stored at $-20^{\circ} \mathrm{C}$ until analysis. Negative controls were terminally sampled at 12 weeks and parameters determined for this group at that time. Deceased fish were removed from the tanks and not replaced. There was only a single mortality observed throughout the experiment. Remaining fish were surrendered to Fort Wayne Metals.

Table 2. Commercial tilapia feed (Purina Mills Aquamax Grower 400 3/32" (2.4mm)) supplemented with linseed or sunflower oil to $5 \%$ of total ingredients. Basic composition below described on package.

\begin{tabular}{|c|c|c|c|c|}
\hline Composition of Feed & & & & \\
\hline Ingredients (g/kg wt) & Control Feed & Treatment Feed & Ingredients \% Control & Treatment \\
\hline Crude Protein (MIN) & 204 & 204 & 45 & 45 \\
\hline Crude Fat (MIN) & 73 & 73 & 16 & 3 \\
\hline Crude Fiber (MAX) & 14 & 14 & 3 & 1.7 \\
\hline Calcium (MIN) & 7.7 & 7.7 & 2.2 & 2.2 \\
\hline Calcium (MAX) & 10 & 10 & 1.2 & 1.2 \\
\hline Phosphorus (MIN) & 5.4 & 5.4 & 0.1 & 0.1 \\
\hline Sodium (MIN) & 0.45 & 0.45 & 0.4 & 0.4 \\
\hline Sodium (MAX) & 1.8 & 1.8 & 10 & 10 \\
\hline Ash (MAX) & 45 & 45 & 5 & 0 \\
\hline Sunflower Oil & 50 & 0 & 0 & 5 \\
\hline Flaxseed Oil & 0 & 50 & & \\
\hline
\end{tabular}




\subsection{Growth}

Growth was determined by measuring length (L) in centimeters and weight (W) in grams using a ruler and an electronic balance. The condition factor (CF) was calculated from this data using the following equation: $\mathrm{CF}=\mathrm{W}^{*} 100 / \mathrm{L}^{3}$ $[12,13]$.

\subsection{Tissue Composition}

Tissue levels of Omega-3 fatty acids were determined using GCMS. Samples were allowed to equilibrate to room temperature before homogenization and the extraction of total lipids using the Bligh and Dyer [14] method. The fatty acid methyl esters were prepared by methylation of the tracylglycerols [14]. They were then separated by gas chromatography using a DB5, $0.25 \mathrm{~mm}$ od, 30 meter, 0.350 $\mathrm{mm}$ film thickness column. The operation parameters were as follows: detector temperature, $280^{\circ} \mathrm{C}$; column temperature, $170^{\circ} \mathrm{C}$ for $16 \mathrm{~min}$, programmed to increase at $2^{\circ} \mathrm{C} / \mathrm{min}$ up to $210^{\circ} \mathrm{C}$, with final holding time of $60 \mathrm{~min}$; carrier gas, hydrogen; splitless injection. For identification of LNA, DHA, and EPA, and other omega-3 fatty acids, the retention times were compared to standards for the methyl esters. Mass spectroscopy was used to quantify/ identify the fatty acids and compute peak area percentages. Quantification of LNA, EPA, and DHA was made against a $\mathrm{C}_{23.0}$ internal standard. To evaluate the efficacy of this methodology and obtain a more detailed analysis the terminal samples were sent to an independent laboratory (Covance Labs, Madison, WI) for detailed analysis.

\subsection{Data Analysis}

Data were checked for normality and if needed was normalized by taking the data to $\log 10$. If the data were normal t-tests and 1-way ANOVA tests were used to determine significance. If the data were found to be not normal and unable to be normalized, then Mann-Whitney and Kruskal-Wallis tests were used to determine significance. Mann-Whitney tests were used to determine if there were differences between replicate tanks before pooling replicate data within each treatment. Out of 12 comparisons, four were significantly different (Appendix A); however, they were not all within the same sample time or the same treatment indicating no tank effects and therefore replicate data for each treatment was pooled to lend greater statistical strength to results. All tests were done using Minitab software (Minitab Incorporated, State College, Pennsylvania, U.S.A.) with an alpha level of 0.05 . All tests used the mean of triplicate data points where relevant.

\section{Results}

\subsection{Condition Factor}

The condition factor significantly increased between 6 and 12 weeks for both $\mathrm{LO}(\mathrm{p}=0.006$, ANOVA $)$ and $\mathrm{SO}(\mathrm{p}<0.000$, ANOVA) (Figure 1). At no time point was LO different from SO. At week 12 the $\mathrm{CF}$ of the $\mathrm{NC}$ was significantly lower than both $\mathrm{LO}$ and $\mathrm{SO}(\mathrm{p}=0.001$ and $\mathrm{p}=0.001$ respectively, t-test) (Figure 1). This indicates that the addition of lipids to the diet contributes to increased growth irrespective of the composition of the lipids.

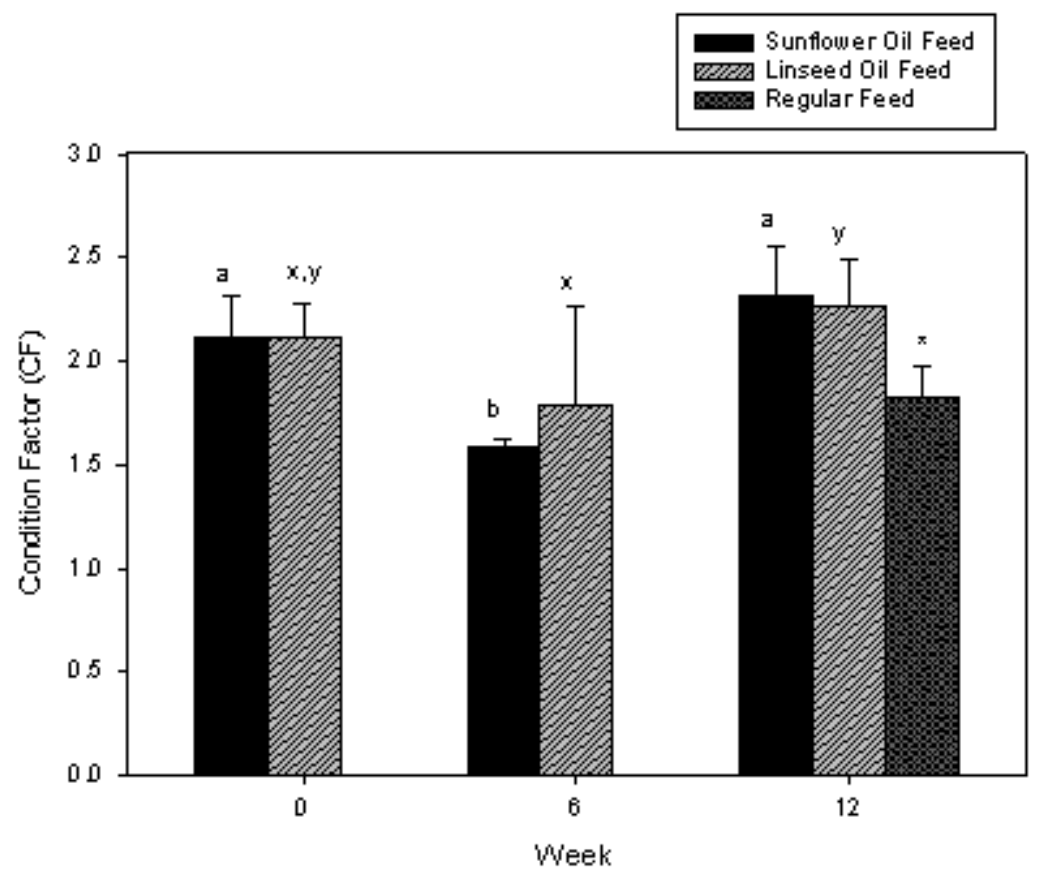

Figure 1. Analysis of condition factor of tilapia at different sampling periods feeding regular, sunflower oil and linseed oil supplemented feeds. Data are means \pm SD. Sample size for LO and SO feeds are 10 fish per feed type at each sample time. Sample size for regular feed is five fish. Letters indicate a significant difference between sample times within a single feed type using ANOVA $(p<0.05)$. Asterisks indicate a significant difference between feed types within a single sample period using T-test $(\mathrm{p}<0.05)$. 
Table 3. Omega-3 fatty acid content of tilapia muscle tissue in area percent when fed regular, sunflower oil and linseed oil supplemented feed as determined by alternate GCMS method. Results expressed as average of two replicates with SD. Regular feed expressed as data from single replicate. Each replicate represents five individual fish.

\begin{tabular}{|c|c|c|c|c|}
\hline Fatty Acid & & Treatment & & \\
\hline & & & & Regular \\
\hline Common Name & Lipid Name & Sunflower Oil & Linseed Oil & \\
\hline$\alpha$-Linolenic Acid (ALA) & & & & 4.49 \\
\hline Eicosapentaenoic Acid (EPA) & C18:3n-3 & $1.96 \pm 0.3$ & $4.20 \pm 3.4$ & 7.93 \\
\hline Eicosatrienoic Acid & C20:5n-3 & $4.60 \pm 1.9$ & $7.13 \pm 0.7$ & 16.27 \\
\hline Docosahexaenoic Acid (DHA) & C22:6n-3 & $68.37 \pm 3.3$ & $52.39 \pm 6.6$ & 71.31 \\
\hline Docosapentaenoic Acid & C22:5n-3 & $10.88 \pm 10.1$ & $21.07 \pm 3.9$ & 0 \\
\hline
\end{tabular}

\subsection{Omega-3 Fatty Acid Retention in Muscle Tissue}

When looking at the results from our modified method no discernible pattern can be seen in the area percent's of the different fatty acids. LO had more ALA and DPA, similar EPA, and lower ETA and DHA compared to SO (Table 3). Also, the NC had more EPA, ETA, and DHA than either SO or LO (Table 3 ). Neither of the supplemented feeds was significantly different from one another for any fatty acid.

When considering the amount of these fatty acids in mg of fatty acid per $\mathrm{g}$ of oil in the flesh, LO is higher in all three fatty acids than SO and NC (Table 4). SO is also higher than $\mathrm{NC}$ in all acids (Table 4). There was no statistical difference between LO and SO for any of the fatty acids.

Table 4. Omega-3 fatty acid content of tilapia muscle tissue in $\mathrm{mg} / \mathrm{g}$ oil when fed regular, sunflower oil and linseed oil supplemented feed as determined by alternate GCMS method. Results expressed as average of two replicates. Regular feed expressed as data from single replicate. Each replicate represents five individual fish.

\begin{tabular}{|c|c|c|c|}
\hline Fatty Acid & Treatment & & \\
\hline & $\begin{array}{c}\text { Sunflower Oil } \\
\text { Feed }\end{array}$ & Linseed Oil Feed & $\begin{array}{c}\text { Regular } \\
\text { Feed }\end{array}$ \\
\hline & & & \\
\hline ALA (mg/g oil) & $1.9 \pm 1.63$ & $55.94 \pm 47.1$ & 1.07 \\
\hline EPA (mg/g oil) & $3.83 \pm 2.51$ & $18.34 \pm 19.3$ & 1.89 \\
\hline DHA (mg/g oil) & $69.88 \pm 64.55$ & $229.33 \pm 237.4$ & 17.00 \\
\hline
\end{tabular}

These results were then compared to the results obtained from the independent lab. Comparison was not possible due to differences in units, but patterns were compared. It is more reliable to use the area percent for the method comparison as the content in Table 4 is based on area percent calculations, oil weights, and a determined correction factor; creating many avenues for error, which is reflected in the high standard deviation of these numbers. The lab reported that LO has higher ALA and ETA, similar EPA and DPA, and lower DHA than SO while NC has higher values than either supplemented feed for all fatty acids (Table 5). The pattern for ALA, EPA, and DHA between LO and SO seen here (Table 5) is the same pattern observed in area percent (Table 3) using our alternate method. The trends for DPA and ETA are different between the two methods. When looking at the relationship between $\mathrm{NC}$ and supplemented feeds, both methods demonstrated that NC had the highest EPA, ETA, and DHA but differed on ALA and DPA.

The independent lab provided us with additional information. They concluded that the regular feed had the highest level of total omega-3 fatty acids followed by LO, then SO (Table 5). LO had the lowest omega- 6 content with SO and NC having similar amounts (Table 5). The LO had the lowest amount of and NC had the highest amount of: saturated, monounsaturated, polyunsaturated, and total fat content (Table 5). 
Table 5. Omega-3 fatty acid content of terminal sample tilapia muscle tissue in $\mathrm{g} / 100 \mathrm{~g}$ of tissue when fed regular, sunflower oil and linseed oil supplemented feed as determined by Covance. Results for terminal sample are expressed as the mean of two replicates and regular feed expressed as a single replicate. Each replicate represents five individual fish pooled for analysis. Three-month post experiment data is from a single fish.

\begin{tabular}{|c|c|c|c|c|}
\hline TERMINAL SAMPLE & & & & \\
\hline Fatty Acid & & Treatment & & \\
\hline Common Name & & & & Regular Feed \\
\hline & Lipid Name & Sunflower Oil Feed & Linseed Oil Feed & \\
\hline$\alpha$-Linolenic Acid (ALA) & C18:3n-3 & & & 0.455 \\
\hline Eicosapentaenoic Acid (EPA) & C20:5n-3 & 0.026 & 0.02 & 0.45 \\
\hline Docosahexaenoic Acid (DHA) & C22:6n-3 & 0.025 & 0.193 & 0.37 \\
\hline & & 0.237 & 0.409 & 1.09 \\
\hline Total Omega-3 Fatty Acids & & & 0.291 & 0.788 \\
\hline Total Omega 6 Fatty Acids & & 0.382 & & 1.62 \\
\hline & & 0.804 & 0.5535 & 2.63 \\
\hline Saturated Fat & & & 0.752 & 1.8 \\
\hline Monounstaurated Fat & & 1.079 & 0.67 & 6.32 \\
\hline Polyunsaturated Fat & & 1.595 & 2.067 & \\
\hline Total Fatty Acids & & 1.138 & & \\
\hline
\end{tabular}

Based on the three-month post experiment data, ALA, DPA, and EPA all lowered over time when treatment feeds were concluded (Table 6). Total omega-3 fatty acids reduced in both groups; however LO retained more than the SO group (Table 6). Also, the total omega-6 fatty acids only lowered for SO. The total fatty acids were reduced by more than half for SO while they did not lower for LO (Table 6).

Table 6. Omega-3 fatty acid content of tilapia muscle tissue $(\mathrm{g} / 100 \mathrm{~g}$ of tissue) 3 months after discontinuing sunflower oil or linseed oil supplemented feed as determined by Covance. Results for terminal sample are expressed as the mean of two replicates and regular feed expressed as a single replicate. Each replicate represents five individual fish pooled for analysis. Three-month post experiment data is from a single fish.

\begin{tabular}{|c|c|c|c|}
\hline \multicolumn{2}{|c|}{$\begin{array}{c}3 \text { MONTH POST EXPERIMENT } \\
\text { SAMPLE }\end{array}$} & \multirow[b]{2}{*}{ Treatment } & \\
\hline Fatty Acid & & & \\
\hline Common Name & $\begin{array}{l}\text { Lipid } \\
\text { Name }\end{array}$ & $\begin{array}{l}\text { Sunflower Oil } \\
\text { Feed }\end{array}$ & $\begin{array}{l}\text { Linseed Oil } \\
\text { Feed }\end{array}$ \\
\hline $\begin{array}{l}\alpha \text {-Linolenic Acid } \\
\text { (ALA) }\end{array}$ & $\mathrm{C} 18: 3 n-3$ & 0.008 & 0.048 \\
\hline $\begin{array}{l}\text { Eicosapentaenoic } \\
\text { Acid (EPA) }\end{array}$ & $C 20: 5 n-3$ & 0.005 & 0.007 \\
\hline $\begin{array}{l}\text { Docosahexaenoic } \\
\text { Acid (DHA) }\end{array}$ & $C 22: 6 n-3$ & 0.063 & 0.106 \\
\hline $\begin{array}{c}\text { Total Omega-3 Fatty } \\
\text { Acids }\end{array}$ & & 0.095 & 0.202 \\
\hline $\begin{array}{l}\text { Total Omega } 6 \text { Fatty } \\
\text { Acids }\end{array}$ & & 0.235 & 0.288 \\
\hline Saturated Fat & & 0.412 & 0.624 \\
\hline Monounstaurated Fat & & 0.474 & 0.794 \\
\hline Polyunsaturated Fat & & 0.317 & 0.47 \\
\hline Total Fatty Acids & & 1.26 & 1.97 \\
\hline
\end{tabular}

\section{Discussions}

Previous work on differing dietary lipid levels suggests that increasing the total lipid intake can confer some health benefits as long as the lipid levels are not excessive [13, 15, 16]. Condition factor was significantly higher in supplemented feeds compared to the standard commercial feed. This supports Chaiyapechara et. al. [13] who demonstrated a significant difference in CF between fish fed a $15 \%$ and a $30 \%$ lipid diet as well as Krion et. al. who tested different lipid sources and found no significant difference between LO and safflower oil in weight gain and growth rate. The higher condition factor indicates that the fish are gaining more mass relative to their length, which is positive for the aquaculture industry as the fillets will be more robust per fish. The increase in mass indicates more fat and protein retention per ounce of weight. This increase subsequently increases the nutritional value of the fillet, especially if the retained fats are higher in omega-3 fatty acids.

Data determining tissue retention of omega-3 fatty acids as determined by the modified method is difficult to interpret. When looking at $\mathrm{mg} / \mathrm{g}$ of oil there is a clear pattern of increasing fatty acid concentrations. LO showed the highest amounts of ALA, EPA, and DHA followed by regular feed. When looking at the area percent this pattern is not clear as LO is higher than SO in two FA, SO is higher than LO in two fatty acids, and regular feed is higher than both in three FA. However, none of the results were statistically significant. We have not demonstrated statistical significance using the modified method and this may be due to multiple factors. We used a differing column and detector than previous work as well as pooling individual fish. The column and detector choice was based on equipment availability and pooling was done due to fish size in early samples and time constraints. 
When we compare these results to those obtained by an independent lab we see similar trends in three of the five fatty acids measured (ALA, EPA, DHA), lending some validity to our method. However for the purposes of demonstrating an increase in omega- 3 fatty acid retention using LO, especially those fatty acids relevant to human health (ALA, EPA, DHA), we did not succeed. We demonstrated an increase in ALA as determined by both methods; however EPA and DHA did not increase and were shown to be the highest in the regular feed using both methods. Previous research seems to have well established an effect of fatty acid composition on muscle composition specifically the increase of omega- 3 fatty acids and a concurrent decrease in omega- 6 fatty acids $[4,5,6,9,10,17$, $18,19]$. We did demonstrate the reduction in omega- 6 fatty acids in LO with similar levels found in SO and NC indicating the addition of omega- 3 fatty acids to the diet decreases the amount of omega- 6 fatty acids stored in the tissue. This may be the result of competitive inhibition of fatty acid desaturases [20]. We may not have shown an increase in omega-3 fatty acids similar to previous research due to pooling of fish from each tank, exposure of fish tissue to oxygen during testing, or other unknown reasons. The lower levels of saturated fat and total fat content in LO suggest both a healthier product for the public as well as healthier overall physiology for the fish. Condition factor is a ratio of length to weight and $\mathrm{LO}$ and $\mathrm{SO}$ had similar CF values and both were significantly higher than $\mathrm{NC}$ at 12 weeks. The CF doesn't indicate if the difference between supplemented feeds and $\mathrm{NC}$ is due to fat gain or muscle gain. However, it is apparent that SO has higher amounts of total fat per $100 \mathrm{~g}$ of tissue than $\mathrm{LO}$ it can be concluded that $\mathrm{LO}$ has more muscle gain than $\mathrm{SO}$, supporting the conclusion that LO produced a more overall healthy fish.

When the three month post experiment data were examined, we determined that all fatty acids (ALA, EPA, DHA) are reduced; however LO retained all three in higher quantities than $\mathrm{SO}$. The total omega-3 fatty acids retained are also higher for LO than SO. This indicates the use of LO increases omega- 3 fatty acid retention compared to SO. The reduction of total fatty acids only for SO further indicates that only LO produced muscle gain.

The addition of linseed oil to commercial feeds is cost effective and simple to use, lending itself to application in the aquaculture and aquaponics industries. It appears to have a positive effect on growth. Previous research suggests this method can increase tissue omega-3 fatty acid levels; however, further research and chemistry needs to be done to establish whether this is possible. If shown to be effective, LO could have a large impact in the industrial setting. Increasing the omega- 3 fatty acids in the fish could enhance the marketability of the product as these fatty acids are becoming well known for their benefits to human health.

The next step in the research would be to examine omega-3 fatty acids as the sole source in the diet. As mentioned previously most commercial feeds contain $15 \%$ fish meal and $1 \%$ fish oil resulting in a ratio of 1.41 wild fish used to every farm fish produced [3]. This is highly inefficient and defeats the purpose of aquaculture potentially replacing unsustainable harvesting of wild populations. Replacing some of the fish oil in the diet with plant based oils such as linseed oil would lower this ratio and potentially make aquaculture more sustainable. Kiron et. al. [16] demonstrated similar physiological results when comparing pollock oil to linseed oil as the sole oil source, indicating this may be a legitimate replacement for fish oils in commercial feeds.

\section{Acknowledgements}

This work would not have been possible without Get Fresh Farms of Fort Wayne Metals providing the aquaponics facility, fish, and grant money to perform the research. Christina Glaze of Fort Wayne Metals deserves many thanks for her ideas, criticisms, and support along the way. We also give my thanks to Leslie Westerhouse of Get Fresh Farms for taking care of the fish.

\section{REFERENCES}

[1] Aguiar, A. C., S. M. Cottica, M. Boroski, C. C. Oliveira, E. G. Bonafe, P. B. Franca, and J. V. Visentainer, J. V. Quantification of Essential Fatty Acids in the Heads of Nile Tilapia (Oreochromis niloticus) Fed with Linseed Oil. Journal of the Brazilian Chemical Society, 22: 643-647, 2011.

[2] Department, F. F. World Aquaculture. 2010. FAO Fisheries and Aquaculture Department Technical Paper, 500: 105pp, 2011.

[3] Naylor, R. L., Goldburg, R. J., Primavera, J. H., Kautsky, N., Beveridge, M. C. M., Clay, J., Troell, M. Effect of aquaculture on world fish supplies. Nature 405 (6790): 1017-1024, 2000.

[4] Justi, K. C., Hayashi, C., Visentainer, J. V., de Souza, N. E., \& Matsushita, M. The influence of feed supply time on the fatty acid profile of Nile tilapia (Oreochromis niloticus) fed on a diet enriched with n-3 fatty acids. Food Chemistry, 80(4), 489-493, 2003. doi:

http://dx.doi.org/10.1016/S0308-8146(02)00317-5.

[5] Visentainer, J. V., N. E. de Souza, M. Makoto, C. Hayashi, and M. R. B. Franco. Influence of diets enriched with flaxseed oil on the $\alpha$-linolenic, eicosapentaenoic and docosahexaenoic fatty acid in Nile tilapia (Oreochromis niloticus). Food Chemistry, 90: 557-560. doi: http://dx.doi.org/10.1016/j.foodchem.2004.05.016., 2005.

[6] Tonial, I. B., F. B. Stevanato, M. Matsushita, N. E. de Souza, W. M. Furuya, and J. V. Visentainer. Optimization of flaxseed oil feeding time length in adult Nile tilapia (Oreochromis niloticus) as a function of muscle omega-3 fatty acids composition. Aquaculture Nutrition, 15: 564-568, 2009. doi: 10.1111/j.1365-2095.2008.00623.x.

[7] Ginty, A. T., Conklin, S. M. Preliminary evidence that acute 
long-chain omega-3 supplementation reduces cardiovascular reactivity to mental stress: a randomized and placebo controlled trial. Biological psychology, 89 (1): 269-272, 2011.

[8] Kiecolt-Glaser, J. K., Belury, M. A., Andridge, R., Malarkey, W. B., Glaser, R. Omega-3 supplementation lowers inflammation and anxiety in medical students: A randomized controlled trial. Brain, behavior, and immunity, 25 (8): 1725-1734, 2011.

[9] de Souza, N. E., Matsushita, M., de Oliveira, C. C., Franco, M. R. B., \& Visentainer, J. V. Manipulation of fatty acid composition of Nile tilapia (Oreochromis niloticus) fillets with flaxseed oil. Journal of the Science of Food and Agriculture, 87(9), 1677-1681, 2007. doi: 10.1002/jsfa.2877.

[10] de Souza, N. E., Stevanato, F. B., Garcia, E. E., Visentainer, J. E. L., Zara, R. F., \& Visentainer, J. V. Supplemental dietary flaxseed oil affects both neutral and phospholipid fatty acids in cultured tilapia. European Journal of Lipid Science and Technology, 110(8), 707-713, 2008. doi: 10.1002/ejlt.200700245.

[11] Tonial, I., Matsushita, M., Furuya, W., Souza, N., Visentainer. Fatty Acid Contents in Fractions of Neutral Lipids and Phospholipids of Fillets of Tilapia Treated with Flaxseed Oil. Journal of the American Oil Chemists' Society, 89 (8): 1495-1500, 2012.

[12] Amlashi, A. S., B. Falahatkar, M. Sattari, and M. Gilani. Effect of dietary vitamin $\mathrm{E}$ on growth, muscle composition, hematological and immunological parameters of sub-yearling beluga $<\mathrm{i}>$ Huso huso $</ \mathrm{i}>$ L. Fish \& Shellfish Immunology, 30: 807-814, 2011.

[13] Chaiyapechara, S., M. T. Casten, R. W. Hardy, and F. M. Dong. Fish performance, fillet characteristics, and health assessment index of rainbow trout $(<\mathrm{i}>$ Oncorhynchus mykiss $</$ i $>$ ) fed diets containing adequate and high concentrations of lipid and vitamin E. Aquaculture, 219: 715-738, 2003.

[14] Joseph, J., Ackman, R. Capillary column gas chromatographic method for analysis of encapsulated fish oils and fish oil ethyl esters: collaborative study. Journal of AOAC International, 75 (3): 488-506, 1992.

[15] Lim, C., M. Yildirim-Aksoy, M. H. Li, T. L. Welker, and P. $\mathrm{H}$. Klesius. Influence of dietary levels of lipid and vitamin $\mathrm{E}$ on growth and resistance of Nile tilapia to $<\mathrm{i}>$ Streptococcus iniae $</ \mathrm{i}>$ challenge. Aquaculture, 298: 76-82, 2009.

[16] Kiron, V., J. Puangkaew, K. Ishizaka, S. Satoh, and T. Watanabe. Antioxidant status and nonspecific immune responses in rainbow trout $(<\mathrm{i}>$ Oncorhynchus mykiss $</ \mathrm{i}>)$ fed two levels of vitamin $\mathrm{E}$ along with three lipid sources. Aquaculture, 234: 361-379, 2004.

[17] Al-Souti, A., Al-Sabahi, J., Soussi, B., Goddard, S.The effects of fish oil-enriched diets on growth, feed conversion and fatty acid content of red hybrid tilapia, (Oreochromis sp.) Food Chemistry, 133 (3): 723-727, 2012.

[18] Karapanagiotidis, I., Bell, M., Little, D., Yakupitiyage, A. Replacement of Dietary Fish Oils by Alpha-Linolenic Acid-Rich Oils Lowers Omega 3 Content in Tilapia Flesh. Lipids, 42 (6): 547-559, 2007.

[19] Mourente, G., Good, J. E., Bell, J. G. Partial substitution of fish oil with rapeseed, linseed and olive oils in diets for European sea bass (Dicentrarchus labrax_L.): effects on flesh fatty acid composition, plasma prostaglandins E2 and $\mathrm{F} 2 \alpha$, immune function and effectiveness of a fish oil finishing diet. Aquaculture Nutrition, 11 (1): 25-40, 2005.

[20] Black, K. D., \& Pickering, A. D. Biology of farmed fish: Sheffield Academic Press, 1998. 